\title{
Hydro-alcoholic Extracts of Roots and Sprouts of Armoracia rusticana: Assessment of Antioxidant and Cytotoxic Activity
}

\author{
ROXANA RACOVICEANU ${ }^{1 \#}$, CLAUDIA FARCAS ${ }^{1 \#}$, ROXANA GHIULAI ${ }^{1 *}$, \\ LAURENTIU VASILE SIMA ${ }^{2 *}$, RAZVAN GABRIEL DRAGOI ${ }^{2 *}$, \\ CRISTINA TRANDAFIRESCU ${ }^{1}$, DIANA ANTAL ${ }^{1}$, MARIUS MIOC ${ }^{1}$, \\ CRISTINA DEHELEAN ${ }^{1}$, CODRUTA SOICA ${ }^{1}$ \\ ${ }^{1}$ Victor Babes University of Medicine and Pharmacy of Timisoara, Faculty of Pharmacy, 2 EftimieMurgu Sq., 300041, Timisoara, \\ Romania \\ ${ }^{2}$ Victor Babes University of Medicine and Pharmacy of Timisoara, Faculty of Medicine, 2 Eftimieurgu Square, 300041, Timisoara, \\ Romania
}

\begin{abstract}
Armoracia rusticana - horseradish is a well-known vegetable used from ancient times and consumed nowadays more for its taste than its pharmacological properties, even though it proved to be a good agent in fighting several health problems. This study focuses on a comparative assessment of several horseradish hydro-alcoholic extracts, obtained from roots and sprouts, respectively, mainly evaluating the antioxidant activity but also a potential cytotoxic effect. The DPPH evaluation revealed that horseradish extracts made from roots or sprouts exhibit a strong antioxidant activity compared to the ascorbic acid used as etalon. The in vitro evaluation established that a significant inhibitory effect on cell viability and morphology of MDA-MB-231 - breast adenocarcinoma cell line was displayed by the hydroalcoholic extracts in a dose-dependent manner.
\end{abstract}

Keywords:Armoraciarusticana, extract, antioxidantactivity, $M D A-M B-231$

\section{Introduction}

Medicinal plants exhibited an uprising interest in the last years due to their use in food industry as well as natural remedies. The healing properties of plants are well known since ancient times and even though science and research have introduced many therapeutic options for various pathologies, an exponential growth in using natural remedies can be observed nowadays [1-3]. Any part of the plant (root, stem, bark, flower or sprouts) can serve as remedy source, depending on the localization and concentration of bioactive components in the plant tissue [4]; these active compounds are responsible for the pharmacological effects of vegetal extracts.

Armoracia rusticana (AR), commonly known as horseradish, belongs to the Brassicaceae family. Horseradish is a perennial vegetable, which grows in places with high humidity; it is cultivated mainly for the white-yellowish roots, but also for the large green leaves and for the sprouts usually used in raw salads. Due to its spicy taste and specific intense flavor, it is used in small quantities; this vegetable is rapidly recognized by its lachrymatory odor and pungent taste.

The first use of horseradish as a medicinal plant dates back to the roman civilization (between 23$79 \mathrm{AD}$ ) when it was used to aid digestion; later, between 40-90 AD, its diuretic effect was also acknowledged [5]. In the $13^{\text {th }}$ century in Denmark, the remedies prepared from AR were consumed in order to treat epilepsy, deafness, skin problems and chest ache; two centuries later, the utilization was extended to alleviate toothache, stomach problems and cough [6]. John Woodall assigned for the first time in 1639 the use of horseradish for scurvy [7] and about in the same period William Coles sustained that horseradish can be successfully used in treating malaria and scurvy [8]. AR remedies were also found to be helpful in many health problems: rheumatism, gout, scurvy, deficient digestion, urinary distress, headache, toothache, sciatica $[6,9]$. 
The spicy flavor characteristic for AR is due to its high content of glucosinolates, secondary metabolites rich in sulfur. Out of the eight glucosinolates found in the AR composition, the following are of interest: sinigrin, glucobrassicin, neoglucobrassicin and gluconasturin [10]. Once reaching the body, glucosinolates decompose with the formation of isothiocyanates and indoles, which are considered to be the main compounds that act as preventive agents for various types of cancer [11-13]. The indole and isothiocyanate derivatives found in cruciferous vegetables stimulated apoptosis in colon cancer cell lines such as LS-174, Caco-2, HCEC [14]. The in vitro studies indicated that a hydrolyzed form of glucosinolate, sinigrine, protects the DNA structure and suppresses the growth of cancerous tumors [15]; in addition, an in vivo rat model study [16] concluded that sinigrine affects the organs involved in the carbohydrates and lipids metabolism, i.e. liver, pancreas and intestine. The hypothesis was that glucosinolates might increase liver's ability to detoxify carcinogens. Sinigrine also reduced lipid blood levels thus suggesting its use in reducing post-meal elevated levels of triglycerides which are significant risk factors for coronary artery disease.

The allyl isothiocyanates found in AR are known as antimicrobial agents against a variety of microorganisms, including pathogens such as Escherichia coli, Helicobacter pylori[17]. Also, horseradish has been successfully used in treating urinary tract infections [18,19] as well as respiratory infections such as bronchitis, cough and other related problems [17].

Brussels sprouts (Brassica oleracea var. Gemmifera), broccoli (Brassica oleracea var. Italica) and other cruciferous vegetables also exhibit a high content in glucosinolates, but Armoracia rusticana contains an amount up to ten times higher in glucosinolates than all other members of the Brassicaceae family, thus exhibiting some particular biological and therapeutic properties [13,20-22].

The high interest in horseradish utilization and bioavailability is illustrated in a recent study conducted by Pavaloiu et al. [23] that proposed a liposomal formulation for the Armoracia rusticanaleaf extract. The liposomes were tested as delivery system and resulted that the extract was gradually released. In these aspects the liposomes proved to be promising carrier for the extracts and ingredients from plants.

While the antimicrobial properties of horseradish are well-known, its effects on cancer cells have much less been subjected to investigation. Sinigrin isolated from horseradish roots showed no proliferating effect on various tumor cell lines [24]. More recently, extracts of different polarities from horseradish roots and juice displayed a strong, non-selective antitumor activity, with the least polar fractions (chloroform, dichloromethane) being the most cytotoxic [25]. In our study, the focus fell on hydro-alcoholic extracts prepared with ethanol, an environmental-friendly solvent which is a frequent ingredient of medicinal preparations. Our aim was to test the cytotoxic activity of both horseradish roots and sprouts on breast cancer cells (MDA-MB-231) and their antioxidant effect, in order to point out the most active extracts.

\section{Materials and methods}

\subsection{Reagents}

AR extracts preparation and analysis: ethanol $96 \%$ and methanol were purchased from Chimreactiv Iasi Romania. The DPPH - 2, 2-diphenyl-1-picrylhydrazyl was purchased from Sigma Aldrich (Germany) and the ascorbic acid from Lach-Ner Company (Czech Republic). All reagents were used as received.

The specific culture medium used to grow the MDA-MB-231 cell line was Dulbecco's Modified Eagle's Medium (DMEM), supplied by ATCC. The culture medium was supplemented with $10 \%$ fetal bovine serum (FCS) and $1 \%$ antibiotic mixture penicillin/streptomycin 10,000 IU/mL. The supplements used to obtain the complete culture media were provided by Gibco, ThermoFisher Scientific. AlamarBlue and Trypan Blue reagents were acquired from Sigma Aldrich, Germany. 


\subsection{Plant material}

The plant material used in this study was harvested in Hunedoara County, Romania in March 2019. At the time of harvest, horseradish had sprouts of 5 to $8 \mathrm{~cm}$ in length (Figure 1A), and the selected roots exhibited a length ranging between 9 and $18 \mathrm{~cm}$ (Figure 1B). After repeated washing, the buds were cut from the root and all plant material was again evaluated and prepared for the extract formation.

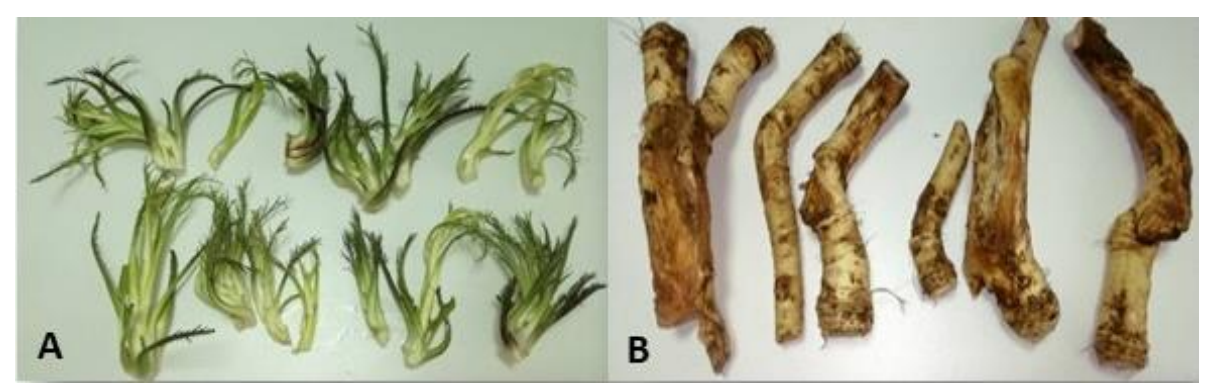

Figure 1. Armoracia rusticana, A- sprouts and B- roots

\subsection{Cell line}

The cells used in this experiment, MDA-MB-231 breast adenocarcinoma cell line, were acquired from American Type Culture Collection (ATCC), ATCC ${ }^{\circledR} \mathrm{HTB}-26^{\mathrm{TM}}$ and were stored until the experiment in liquid nitrogen, at $-196^{\circ} \mathrm{C}$.

\subsection{Extracts preparation}

Hydro-alcoholic extracts were prepared from the horseradish roots and sprouts, respectively, in order to evaluate them comparatively. Two different ratios of ethanol and distilled water were used:a ratio of 1:4 water:ethanol (v/v) and 1:4ethanol:water(v/v). The fresh vegetal material was shredded and then placed in containers; the solvent was added in a ratio of $5 \mathrm{~g}$ raw plant material to $10 \mathrm{~mL}$ solvent. The mixture was kept for $48 \mathrm{~h}$, at $4{ }^{\circ} \mathrm{C}$ in the refrigerator and then sonicated for $30 \mathrm{~min}$ in an Elma S120 ultrasonic bath from Elmasonic. The mixture was then filtered and deposited in dark and cold containers until further analysis.

Table 1 presents the solvent mixtures used in the preparation of Armoracia rusticana extracts.

Table 1. Water-ethanol ratio used for the extracts

\begin{tabular}{|l|l|l|}
\hline Sample & Solvent & Vegetal material \\
\hline M1 & $1: 4$ ethanol:water(v/v) & Sprout \\
\hline M2 & $1: 4$ water:ethanol & \multirow{2}{*}{ Root } \\
\hline R1 & $1: 4$ ethanol:water(v/v) & \\
\hline R2 & $1: 4$ water:ethanol & \\
\hline
\end{tabular}

\subsection{Antioxidant activity evaluation - DPPH assay}

A DPPH (2,2-diphenyl-1-picrylhydrazyl) solution was used to evaluate the antioxidant activity of AR extracts. A $1 \mathrm{mM}$ DPPH solution was prepared by dissolving $0.008 \mathrm{~g} \mathrm{DPPH}$ in $20 \mathrm{~mL}$ methanol. After preparation, the DPPH methanol solution has been stored in the dark at temperatures not exceeding $4{ }^{\circ} \mathrm{C}$ in order to avoid degradation. A $4 \mathrm{mg} / \mathrm{mL}$ ascorbic acid solution in ethanol, obtained by dissolving $40 \mathrm{mg}$ ascorbic acid in $10 \mathrm{~mL}$ ethanol, was used as standard.

The antioxidant activity of the extracts was assessed according to a method previously published in the literature [26]. Briefly, $0.5 \mathrm{~mL}$ AR extract, $2 \mathrm{~mL}$ appropriate solvent (the same solvent used to obtain the extract) and $0.5 \mathrm{~mL} 1 \mathrm{mM}$ DPPH solution were used; measurements were performed for 20 minutes by using a T70 UV / VIS spectrophotometer (PG Instruments Ltd.) in Kinetic mode at $516 \mathrm{~nm}$ wavelength. The absorbance values of DPPH mixed with the extracts and DPPH mixed with standard (ascorbic acid), respectively, were recorded. 
Antioxidant activity expressed as a percentage (\% AOA) was calculated using the following formula:

where:

$$
\operatorname{AOA}(\%)=\frac{A_{\text {DPPH }}-A_{\text {Sample }}}{A_{\text {DPPH }}} \times 100
$$

AOA (\%) - antioxidant activity of the extracts, expressed as a percentage;

ADPP - DPPH absorbance;

Asample - sample absorbance.

\subsection{Cell culture}

Throughout the study, cells were kept under standard conditions, in a Steri-Cycle i160 incubator (Thermo Fisher Scientific, USA), in a humidified atmosphere, enriched with $5 \% \mathrm{CO}_{2}$ and $37^{\circ} \mathrm{C}$. Cells confluence was monitored daily with the Olympus IX73 inverted microscope, equipped with DP74 camera and CellSense Dimension software. The cells were trypsinized every $48 \mathrm{~h}$ and cultured in T75 culture plates. Cell count was determined automatically with the Countess TM II Automated Cell Counter in the presence of Trypan Blue, in a 1:1 volume ratio.

\subsection{Cell viability assessment by means of AlamarBlue method}

The AlamarBlue $(\mathrm{AB})$ assay was performed on an invasive breast adenocarcinoma cell line MDA-MB-231 in order to assess the potential cytotoxic effects of the horseradish extracts. The principle of the $\mathrm{AB}$ test is based on a colorimetric reaction in which resazurin, a dark blue compound, is reduced by the mitochondrial reductase within viable cells to resorufin, a pink compound with intense fluorescence; thus, quantitative results can be obtained spectrophotometrically in terms of cell viability. Briefly, the MDA-MB-231 cell line was cultured in 96-well plates at a density of $10^{4}$ cells/well in $200 \mu \mathrm{L}$ medium per well. The cells were allowed to grow for $48 \mathrm{~h}$, until they reached the optimal confluence. After this step, the medium was removed and the cells were treated with $200 \mu \mathrm{L}$ of fresh medium containing the extract samples in concentrations of $10 \mu \mathrm{g} / \mathrm{mL}, 20 \mu \mathrm{g} / \mathrm{mL}$ and 30 $\mu \mathrm{g} / \mathrm{mL}$, respectively. After $24 \mathrm{~h}, 20 \mu \mathrm{L}$ of $\mathrm{AB} /$ well was added and the plate was incubated for 3 hours in order to allow the colorimetric reaction to take place. Cell viability was then determined by reading the absorbance values at two wavelengths $570 \mathrm{~nm}$ and $600 \mathrm{~nm}$, respectively, by using the xMark TM Microplate Spectrophotometer, Biorad.

\section{Results and discussions}

\subsection{Antioxidant activity}

The evolution of the antioxidant activity of AR extracts throughout the experiment is depicted in Figure 2.

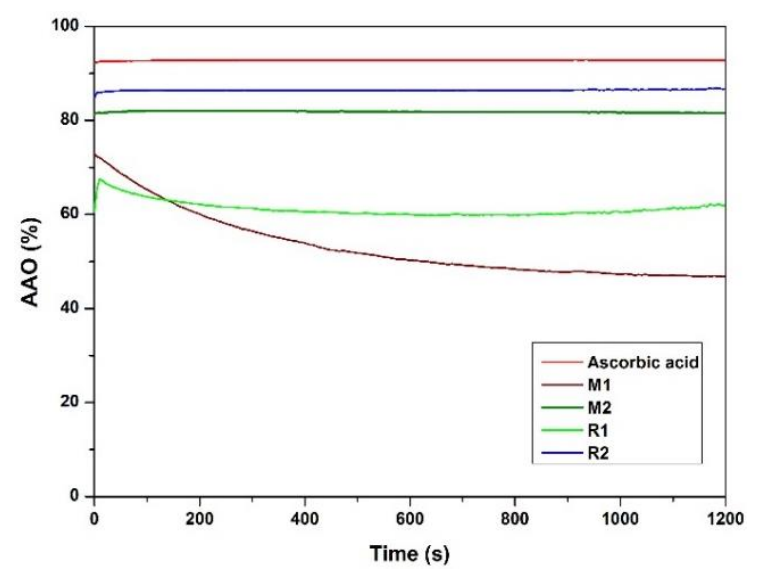

Figure 2. The evolution of the antioxidant activity ofArmoracia Rusticana extracts during the experiment 
One can notice that the analyzed extracts exhibit a significant antioxidant activity, as compared to the $4 \mathrm{mg} / \mathrm{mL}$ ascorbic acid solution used as reference. The highest values of antioxidant activity were reached by extracts $\mathrm{R} 2$ and $\mathrm{M} 2$ which were prepared by using a ratio of 1:4 water:ethanol (v/v), thus suggesting that a high content of ethanol is needed for the extraction of vegetal compounds with antioxidant properties. The other two extracts, R1 and M1, which were obtained by using a ratio of 1:4 ethanol:water (v/v), also exhibit a significant antioxidant activity, but lower than the previous ones.

If we compare the antioxidant activity of the horseradish root extracts, R1 and R2 (Figure 3) one can notice that the highest value was recorded for sample R2 (solvent containing 1:4 water:ethanol (v/v)). Sample R2 reaches a value of $86.9 \%$ which is comparable to the $92.9 \%$ value recorded for the 4 $\mathrm{mg} / \mathrm{mL}$ solution of ascorbic acid used as reference. In addition, sample R1 exhibits a relatively high antioxidant activity with a maximum value of $67.5 \%$; also, the maximum antioxidant activity is reported at the beginning of the experiment followed by a decrease at around $60 \%$ which remains unchanged throughout the experiment.
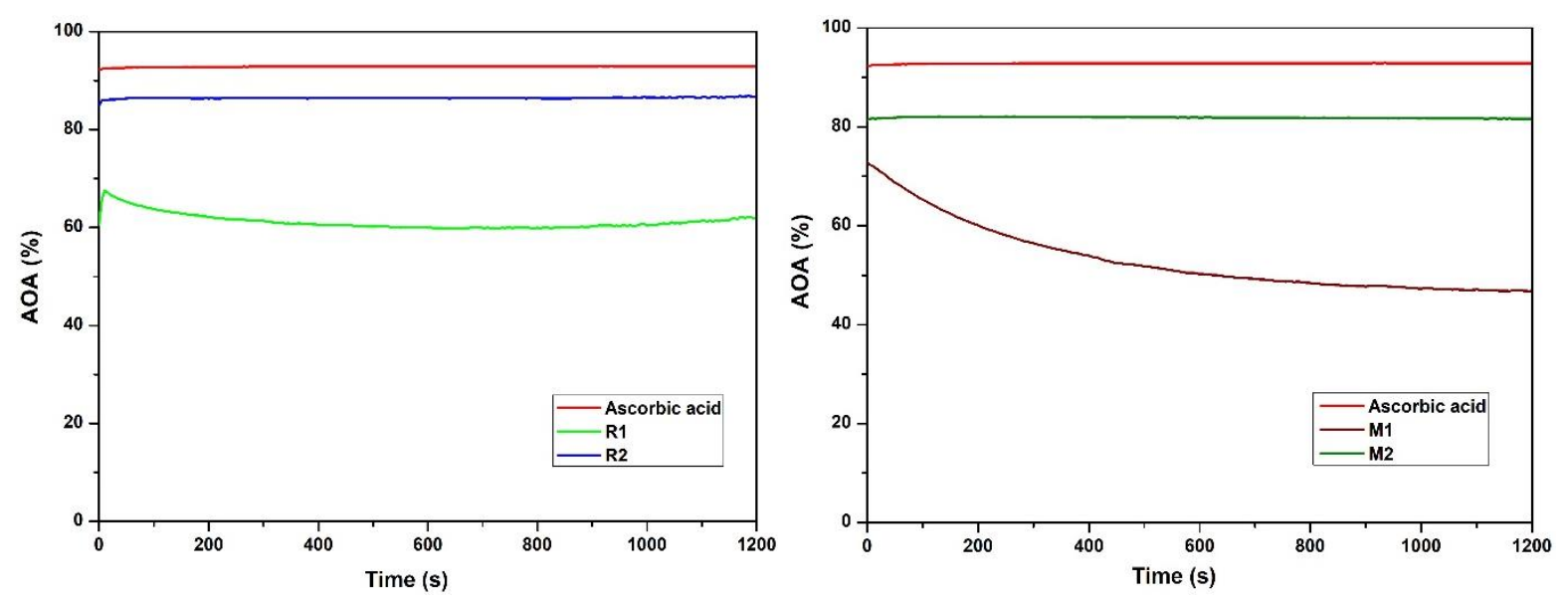

Figure 3. The evolution of the antioxidant activity for $\mathrm{R} 1, \mathrm{R} 2$ and $\mathrm{M} 1, \mathrm{M} 2$ extracts during the experiment

When the antioxidant activity of horseradish sprouts extracts, M1 and M2, is compared, the highest value $(82.1 \%$ ) can be noticed for sample M2 (Figure 3); a maximum of $72.8 \%$ was registered for sample M1 followed by a decrease to approximately $50 \%$.

In both cases, R2 and M2 show a constant antioxidant activity during the 20 min of the experiment, while R1 and M1 exhibit a maximum value at the beginning of the experiment which gradually decreases afterwards.

The high values obtained for the antioxidant activity of all AR extracts are due to the chemical composition of the raw materials used in the extraction process, roots and sprouts. Rivelli et al. reported a high content in vitamin $\mathrm{C}$ in both roots and leaves of horseradish [27], compound with strong antioxidant activity which was used as reference in our experiment. The antioxidant activity of horseradish roots and leaves was also assessed by Calabrone et al. who revealed that hydroalcoholic extracts exhibited a stronger DPPH radical scavenging activity than methanolic ones and attributed it to the higher content in phenolic compounds; also the main phenolic compounds are represented by flavonoids [28]. The results reported in the current paper are in line with those reported in a pilot study by Biller et al. who calculated that $1 \mathrm{~g}$ dry substance of horseradish exhibited an antioxidant potential equal to 4.31 to $8.78 \mathrm{mg}$ of vitamin $\mathrm{C}$ [29].

\subsection{In vitro cell MDA-MB-231 cell line testing.Morphological aspects.}

The morphological changes induced by the tested samples, extracts and corresponding solvents, on breast adenocarcinoma cell line MDA-MB-231 are presented in the Figures 4-7. 


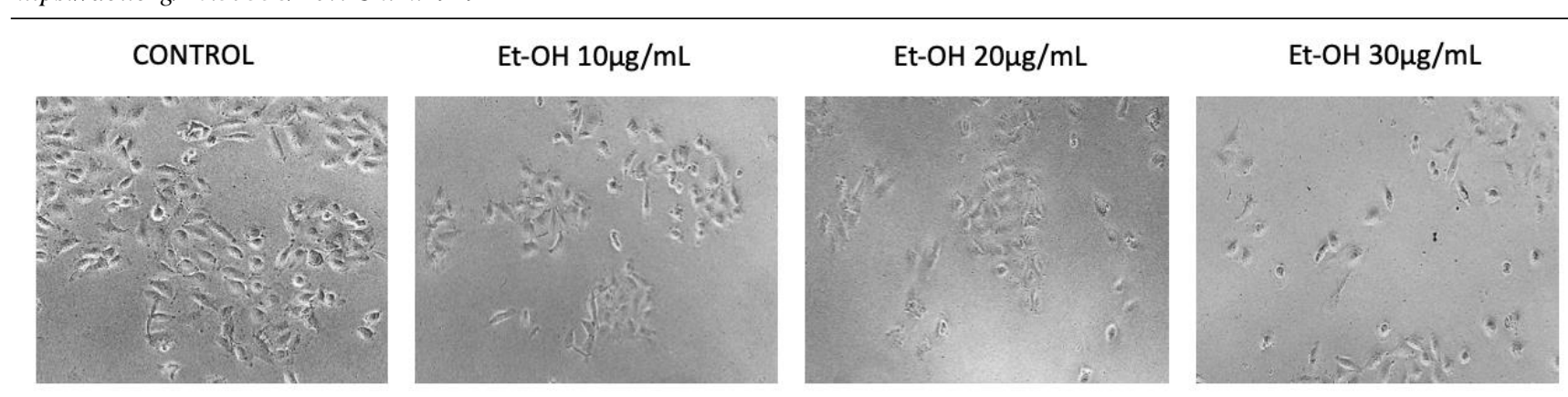

Figure 4. Morphological changes caused by corresponding amounts of solvent ( $20 \%$ ethanol) on the MDA-MB-231 cell line, following a $24 \mathrm{~h}$ stimulation. The pictures were taken in phase contrast microscopy with Olympus IX73 inverted microscope, at 10x magnification.

CONTROL

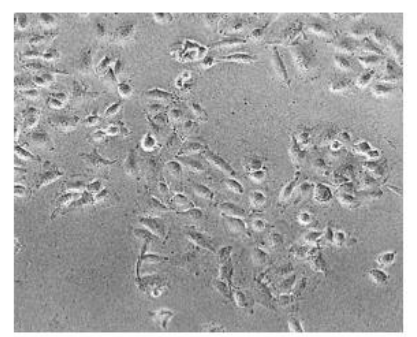

Et-OH $10 \mu \mathrm{g} / \mathrm{mL}$

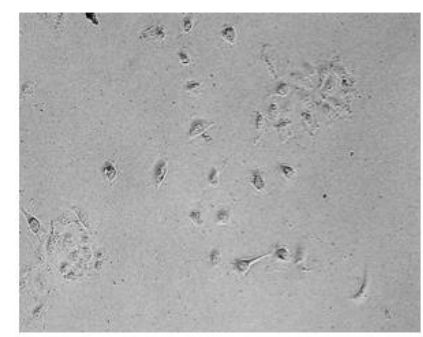

$\mathrm{Et}-\mathrm{OH} 20 \mu \mathrm{g} / \mathrm{mL}$

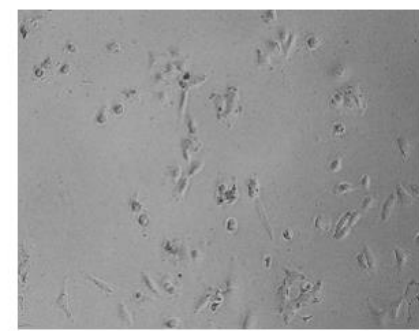

$\mathrm{Et}-\mathrm{OH} 30 \mu \mathrm{g} / \mathrm{mL}$

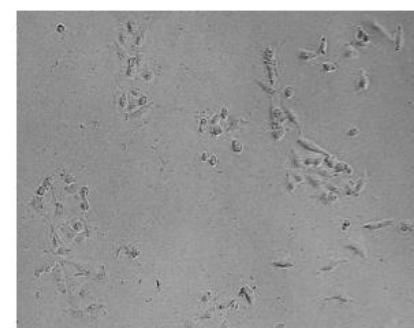

Figure 5. Morphological changes caused by corresponding amounts of solvent ( $80 \%$ ethanol) on the MDA-MB-231 cell line, following a $24 \mathrm{~h}$ stimulation. The pictures were taken in phase contrast microscopy with Olympus IX73 inverted microscope, at 10x magnification

As one can see in Figure 4, the hydro-alcoholic solvent with a content of $20 \%$ ethanol did not induce significant changes in the morphology of the breast adenocarcinoma - MDA-MB-231 cells. In contrast, Figure 5 revealed that the cells exposed to the hydro-alcoholic solvent containing $80 \%$ ethanol manifested a significant decrease in cell confluence. In addition, several morphological changes could be noticed, mainly after stimulation with the highest volume of solvent, corresponding to $30 \mu \mathrm{g} / \mathrm{mL}$ vegetal extract. In this case, the cells lose their shape and became round thus revealing specific features of apoptosis.

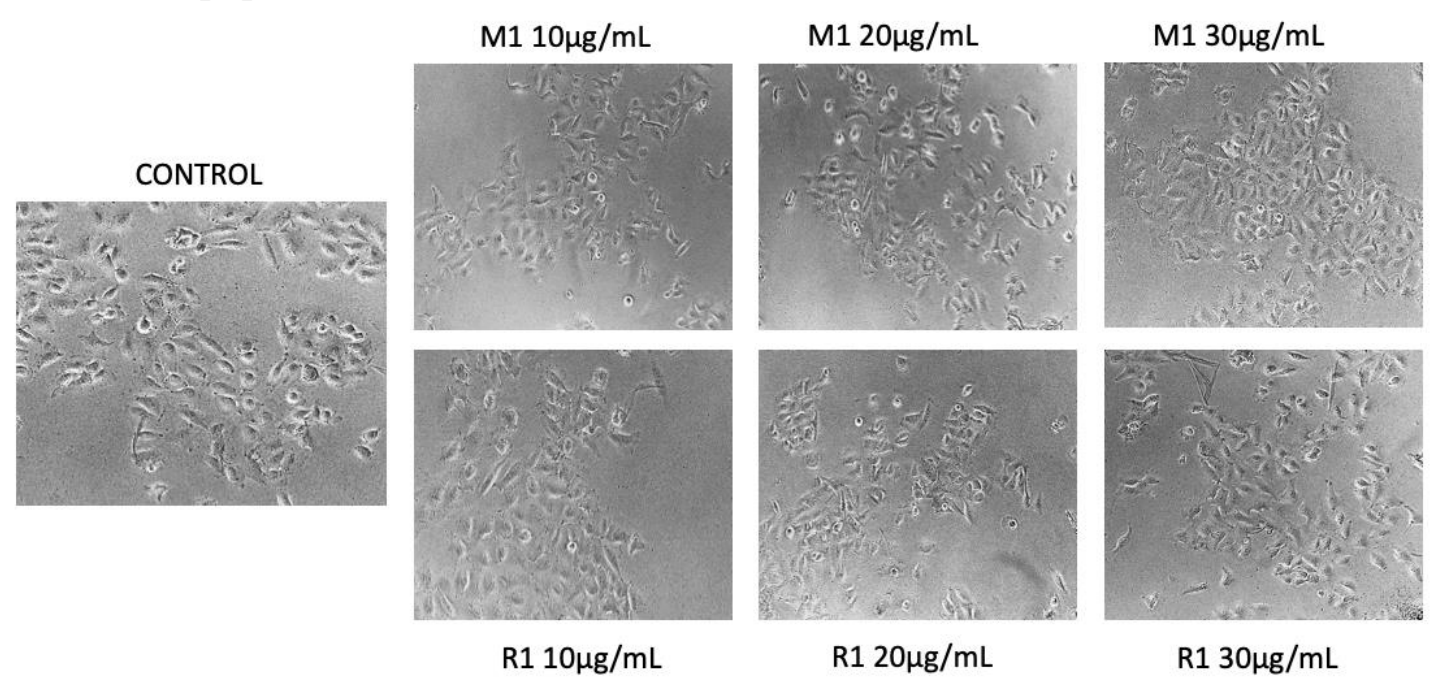

Figure 6. Morphological changes induced by horseradish extracts obtained with a hydro-alcoholic solvent with $20 \%$ ethanol, following $24 \mathrm{~h}$ stimulation. The pictures were taken in phase contrast microscopy with Olympus IX73 inverted microscope, at 10x magnification 
After a stimulation of $24 \mathrm{~h}$ with all test concentrations $(10,20$ and $30 \mu \mathrm{g} / \mathrm{mL}$, respectively) of R1 extract (Figure 6), MDA-MB-231 cells manifested a significant confluence decrease; in contrast, exposure of MDA-MB-231 cells to the same concentrations of M1 extract induced a slight increase of cellular confluence, compared to control cells (cells treated with culture medium).

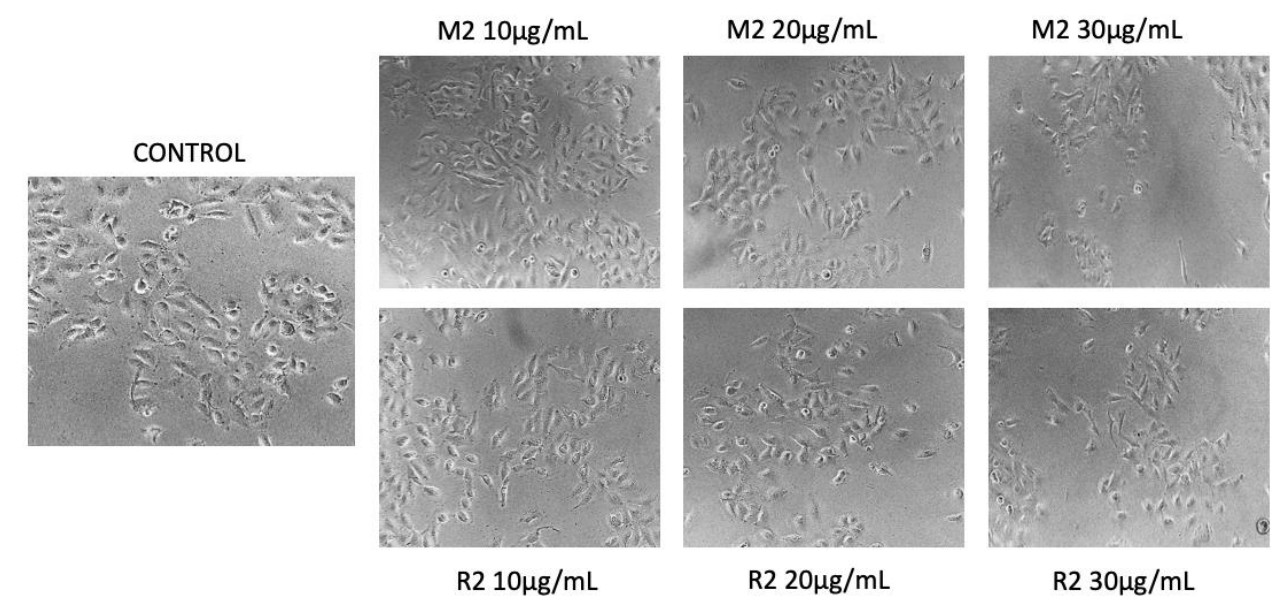

Figure 7. Morphological changes induced by horseradish extracts obtained with a hydro-alcoholic solvent of $80 \%$ ethanol, following $24 \mathrm{~h}$ stimulation. The pictures were taken in phase contrast microscopy with Olympus IX73 inverted microscope, at 10x magnification

The confluence of breast adenocarcinoma cells - MDA-MB-231 was significantly reduced after 24h stimulation with M2 and R2 extracts added in concentration of $30 \mu \mathrm{g} / \mathrm{mL}$; a confluence around $70 \%$ was reported (Figure 7). However, cells treated with lower concentrations $(10$ and $20 \mu \mathrm{g} / \mathrm{mL}$, respectively) of extracts exhibited different responses; after stimulation with R2 extract the cells expressed 80-85\% confluence, whereas cells exposed to concentrations of 10 and $20 \mu \mathrm{g} / \mathrm{mL}$ of M2 extracts, respectively, did not show diminished confluence.

\subsection{In vitro cell MDA-MB-231 cell line testing. Cell viability assessment.}

The cell viability assessment was performed by means of Alamar Blue test in order to evaluate the effect of horseradish extracts on the viability of MDA-MB-231 breast cancer cells which were stimulated for $24 \mathrm{~h}$; initially, medium treated cells were used as control. However, due to the fact that the hydro-alcoholic solvents reduced cell viability and induced changes in cell morphology, it was decided that the experimental results should be normalized against to the solvent used for the preparation of each type of extract, respectively, used as control. Thus, the effect of the extracts on MDA-MB-231 cell viability could be reported independently of the solvent-induced effect. The obtained results are included in Figure 8.
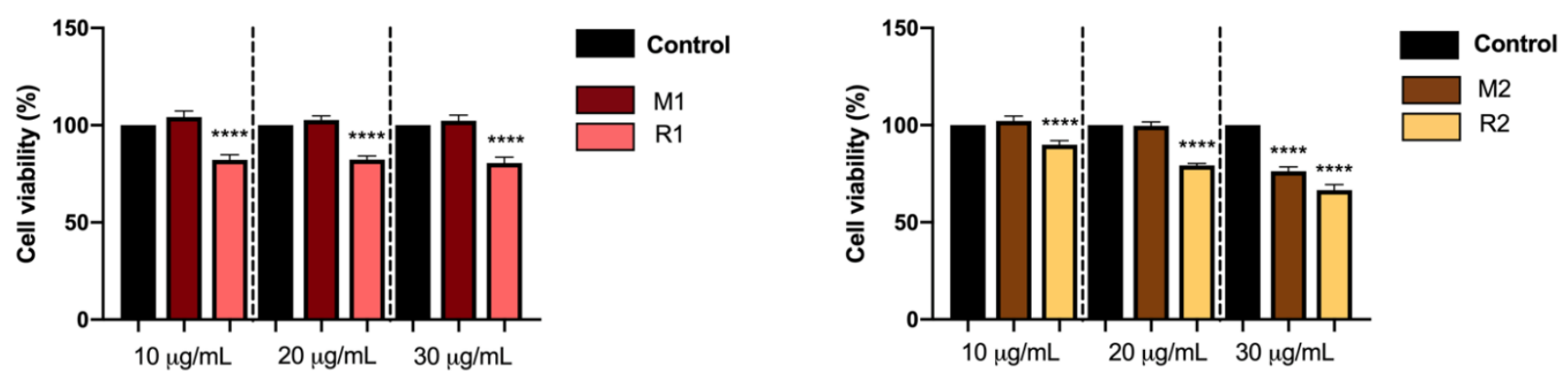

Figure 8. Graphical representation of MDA-MB-231 cells, following 24 h stimulation with hydroalcoholic extracts of horseradish M1,R1 and M2, R2. The data represent the mean values \pm SD of three independent experiments. One-way ANOVA analysis was applied to evaluate the statistical differences followed by Tukey's multiple comparisons test $(* * * * p<0.0001)$ 
As presented in figure 9, the hydro-alcoholic extract of horseradish R1 exerts an inhibitory effect on the viability of the breast adenocarcinoma cells - MDA-MB-231, showing a dose-dependent viability rate, namely: $86.22 \%, 82.27 \%$ and $80.59 \%$ for each applied concentration, respectively. Following stimulation with M1 extracts, a slight increase of cell viability was noticed compared to the solvent $(20 \%$ Et-OH). Thus, depending on the extract concentration, the viability rate recorded for MDA-MB-231 cells were 104.22\%, 102.67\% and 102.29\%, respectively (Figure 9).

For the hydro-alcoholic extracts with a content of $80 \%$ ethanol, a slight increase in the viability of breast adenocarcinoma cells was recorded after stimulation with the lowest concentration of the M2 extract $(10 \mu \mathrm{g} / \mathrm{mL})$. In contrast, when the $30 \mu \mathrm{g} / \mathrm{mL}$ concentration was used, both M2 and R2 extracts induced a significant cytotoxic effect of MDA-MB-231 cells, displaying a proliferation rate of $76.32 \%$ in the case of M2 extract and a rate of $66.52 \%$ viability after stimulation with R2 extract. Nevertheless, the MDA-MB-231 cells treated with the medium concentration of $20 \mu \mathrm{g} / \mathrm{mL}$ horseradish root extract (R2) manifested a diminished viability percentage of $79.25 \%$, thus revealing an average cytotoxic activity.

The antiproliferative effects of horseradish extracts against the MDA-MB-231 cancer cells were also reported by Đurić et al. who revealed that chloroform and dichloromethane extracts exert a highly potent cytotoxic activity as opposed to butanol and water extracts; the antiproliferative effect was assessed by means of IC50 value[30]. The authors hypothesized that the high content of liposolubleisothiocyanates in the extracts obtained with organic solvents was responsible for the reported antiproliferative activity.

The horseradish extracts were also analyzed in terms of polyphenol content by using the same organic solvents, chloroform and dichloromethane[25]; the results revealed significant non-selective antiproliferative activity in particular against liver, breast and lung cancer cells. These results were associated with a high content of polyphenolic compounds, in particular for the dichloromethane extracts; necrosis was employed as the main mechanism for the reported cell death.

Nevertheless, the use of organic solvents raise the issue of purity for the final extracts, the presence of organic residues in pharmaceutical products, even in trace amounts, being regulated by international standards. Therefore, non-toxic solvents, such as water or ethanol, are required in order to avoid toxicity issues. Herz et al. prepared aqueous horseradish extracts that revealed high concentrations of volatile and non-volatile glucosinolates, amino acids and phenolic compounds; glucosinolates are later hydrolyzed to allyl- and phenylethylisothiocyanates[9]. The authors reported a strong antiinflammatory activity caused by a dual inhibition of the aminoacid metabolism with less severe side effects compared to selective COX blockers; in addition, the effects were not mediated by isothiocyanates.

The current study reports the dose-dependent antiproliferative activity of hydroalcoholic horseradish extracts prepared with two concentrations of ethanol, the highest inhibition of cell viability being exerted by the highest ethanol content $(80 \%)$; these results are in line with previously reported data as mentioned above.All tested samples, regardless of the water:ethanol ratio, showed considerable antioxidant activity, with values above 65\%; therefore, we may assume that the antiproliferative activity is related to the composition in antioxidant agents such as polyphenols. However, it should be noted that a slight stimulation of breast adenocarcinoma cell viability was recorded for extracts obtained from sprouts (M1 and M2) while all horseradish root extracts exhibited a clear antiproliferative effect on the MDA-MB-231 cell line, after 24h stimulation.

\section{Conclusions}

The comparative analysis of the hydroalcoholic extracts of horseradish roots and sprouts revealed that the highest value of antioxidant activity was reached when a mixture of $20 \%$ water and $80 \%$ ethanol was used as solvent while using horseradish root as raw vegetal material (R2).

Following in vitro experiments conducted for the analysis of cell morphology and viability by means of Alamar Blue technique one could notice that the most significant inhibitory effect on cancer 
cell viability was exerted by extracts $\mathrm{M} 2$ and $\mathrm{R} 2$ at the highest tested concentration $(30 \mu \mathrm{g} / \mathrm{mL})$; a dose-dependent antiproliferative activity can therefore be reported.

Further studies are needed in order to elucidate the relationships between various compounds of horseradish extracts and their antiproliferative activity and mechanism of action.

Acknowledgments:This work was supported by an Internal grant at "Victor Babes" University of Medicine and Pharmacy,Grant III-C5-PCFI-2017/2018-04 ROINEXTRAMAM, Project Manager: AvramStefana

\section{References}

1. MCGAW, L.J, SRIVASTAVA, A.K., LIN, C-H, STEENKAMP V., Book Review: Medicinal Plants for Holistic Healing.,Front Pharmacol.10, 2019, 1-2.

2. DAR, R.A., SHAHNAWAZ, M., QAZI, P.H., QAZI, H., General overview of medicinal plants: A review,JPhytopharmay,6,2017, 349-351.

3. ANAND, U., JACOBO-HERRERA, N., ALTEMIMI, A., LAKHSSASSI, N.,A comprehensive review on medicinal plants as antimicrobial therapeutics: Potential avenues of biocompatible drug discovery,Metabolite,9, 2019, 1-13.

4. PETROVSKA, B.B.,Historical review of medicinal plants' usage, Pharmacogn Rev.6, 2012, 1-5.

5. COURTER, J.W., RHODES, A.M., Historical notes on horseradish,Econ Bot.,23,1969, 156-164.

6. WEDELSBÄCK, B.K., OLSSON, K.M.,Introduction and use of horseradish (Armoracia rusticana) as food and medicine from antiquity to the present: Emphasis on the nordic countries,J Herbs, Spices Med Plants, 17, 2011, 197-213.

7. WOODALL, J.,The surgeons mate, or, Military \& domestique surgery. Early English Books, London: Printed by Rob Young for Nicholas Bourne; 1639.

8. COLES, W.,The art of simpling: an introduction to the knowledge and gathering of plants wherein the definitions, divisions, places, descriptions, differences, names, virtues, times of flourishing, Herb Lovers Book Club, 1938.

9. HERZ, C., TRAN, H.T.T., MÁRTON, M.R., MAUL, R., BALDERMANN, S., SCHREINER, M., LAMY, E., Evaluation of an Aqueous Extract from Horseradish Root (Armoracia rusticana Radix) against Lipopolysaccharide-Induced Cellular Inflammation Reaction,Evidence-based Complement Altern Med., 2017,1-10.

10.ALNSOUR, M., KLEINWÄCHTER, M., BÖHME, J., SELMAR, D.,Sulfate determines the glucosinolate concentration of horseradish in vitro plants (Armoracia rusticana Gaertn., Mey. \& Scherb.), J Sci Food Agric.93, 2013, 918-23.

11.RINZLER, C.A.,New Complete Book Herbs Spices and Condiments, Checkmark Books, 2001. 1422.

12. HAYES, J.D., KELLEHER, M.O., EGGLESTON, I.M.,The cancer chemopreventive actions of phytochemicals derived from glucosinolates, Eur J Nutr.,47, 2008, 73-88.

13. KADIR, N.H.A., DAVID, R., ROSSITER, J.T., GOODERHAM, N.J.,The selective cytotoxicity of the alkenyl glucosinolate hydrolysis products and their presence in Brassica vegetables, Toxicology., 334,2015, 59-71.

14. BONNESEN, C., EGGLESTON, I.M., HAYES, J.D.,Dietary Indoles and Isothiocyanates That Are Generated from Cruciferous Vegetables Can Both Stimulate Apoptosis and Confer Protection against DNA Damage in Human Colon Cell Lines,Cancer Res.,61, 2001,6120-6130.

15.PATEL, D.K., PATEL, K., GADEWAR, M., TAHILYANI, V.,A concise report on pharmacological and bioanalytical aspect of sinigrin,Asian Pac J Trop Biomed. 2, 2012,446-448.

16. OKULICZ, M.,Multidirectional Time-Dependent Effect of Sinigrin and Allyl Isothiocyanate on Metabolic Parameters in Rats,Plant Foods Hum Nutr.,65, 2010,217-224. 
17. PARK, H.W, CHOI, K.D., SHIN, I.S.,Antimicrobial activity of isothiocyanates(itcs) extracted from horseradish(armoracia rusticana) root against oral microorganisms. Biocontrol Sci,.18, 2013, 163-168.

18. BAUMAN,H., EBROM, N.,Food as Medicine - Horseradish (Armoracia rusticana, Brassicaceae), American Botanical Council,12, 2015.

19. WEDELSBÄCK, B.K., Biodiversity in Nordic Horseradish (Armoracia rusticana) Studies with Respect to Conservation and Utilization,Doctoral Thesis, 2014, 1-47.

20. HIGDON, J.V., Delage, B., Williams, D.E., Dashwood, R.H.,Cruciferous vegetables and human cancer risk: epidemiologic evidence and mechanistic basis,Pharmacol Res.55, 2007,224-236.

21. WICZK, A., HOFMAN, D., KONOPA, G., HERMAN-ANTOSIEWICZ, A.,Sulforaphane, a cruciferous vegetable-derived isothiocyanate, inhibits protein synthesis in human prostate cancer cells. Biochim Biophys Acta - Mol Cell Res.1823, 2012,1295-1305.

22. AGNETA, R., MÖLlERS, C., RIVELli, A.R., Horseradish (Armoracia rusticana), a neglected medical and condiment species with a relevant glucosinolate profile: a review, Genet Resour Crop Evol, 60, 2013, 1923-1943.

23. PAVAlOIU, R.D., SHA'ATI F., BUBUEANU, C., HLEVCA, C., NECHIFOR, G., Design and Evaluation of a Delivery System Based on Liposomes for Armoracia rusticana Extract, Rev. Chim., 7(70), 2019, 2347-2349.

24. WEIL, M.J., ZHANG, Y., NAIR, M.G., Colon cancer proliferating desulfosinigrin in wasabi (Wasabia japonica), Nutr. Cancer, 48(2), 2004, 207-213.

25. PETROVIĆ, V., ČETOJEVIĆ-SIMIN, D., MILANOVIĆ, M., VULIĆ, J., MILIĆ, N., Polyphenol rich horseradish root extracts and juice: In vitro antitumor activity and mechanism of action. Vojnosanitetski pregled., 2020, 1-26.

26. KEDARE, S.B., SINGH, R.P.,Genesis and development of DPPH method of antioxidant assay,J Food SciTech,48,2011, 412-22.

27. RIVELli, A.R., CARUSO, M.C., DE MARIA, S., GALGANO, F., Vitamin C content in leaves and roots of horseradish (Armoracia rusticana): Seasonal variation in fresh tissues and retention as affected by storage conditions, Emirates J Food Agric., 29, 2017, 799-806.

28. CALABRONE, L., LAROCCA, M., MARZOCCO, S., MARTELli, G., ROSSANO, R.,Total Phenols and Flavonoids Content, Antioxidant Capacity and Lipase Inhibition of Root and Leaf Horseradish (Armoracia rusticana) Extracts, Food Nutr Sci.,6, 2015, 64-74.

29. BILLER, E., WASZKIEWICZ-ROBAK, B., OBIEDZIŃSKI, M., KALINOWSKI, K., Antioxidant properties of horseradish (Armoracia rusticana) - Pilot Studies, Pol. J. Appl. Sci., 4, 2018, 55-59.

30. ĐURIC, L., CETOJEVIC-SIMIN, D., MILANOVIC, M.,Examination of antiproliferative effects of the horseradish extracts, Porto Biomed J.,2(5), 2017, 213.

$\overline{\text { Manuscript received: } 25.02 .2020}$ 